\title{
FOETOMATERNAL OUTCOME AND PLACENTAL CHANGES IN ECLAMPTIC PATIENTS
}

\author{
Moly Sam Kodiplackal' ${ }^{1}$ Preeja Chettoor $^{2}$
}

${ }^{1}$ Assistant Professor, Department of Obstetrics and Gynaecology, Government Medical College, Kozhikode. ${ }^{2}$ Senior Resident, ESI Hospital, Udyogamandal, Ernakulam.

\section{ABSTRACT}

\section{BACKGROUND}

The aim is to study the macroscopic and microscopic changes in placenta of eclamptic women and to study the association between these changes in placenta and maternal foetal outcome.

\section{MATERIALS AND METHODS}

This case control study done at IMCH, Govt. Medical College, Kozhikode, Kerala between Jan. $1^{\text {st }} 2011$ to $31^{\text {st }}$ Dec. 2011 . Ninety cases included in this study, 45 were cases and 45 were controls. All cases of antepartum and intrapartum eclampsia included in this study after excluding all other causes for seizure during pregnancy.

\section{RESULTS}

The incidence of eclampsia was $0.32 \%$ in IMCH, Kozhikode during the study period of 1 year and it was less than National Average of $1.5 \%$. Eclampsia occurred in the age group of 18 to 24 years (51\%). The average age of cases was 25.4 years and 24.68 years for control. Haemoconcentration is considered as the hallmark of eclampsia and it was present in 19 cases (HCT >42). Incidence of IUGR and low birth weight was more in eclampsia with significant decrease in APGAR score, and hence NICU admission was also high in eclampsia.

\section{CONCLUSION}

Eclampsia is common in low socioeconomic group and it results in preterm and low birth weight babies. Placental weight and diameter is less in eclamptic women. Macroscopic and microscopic changes in placenta show that placenta has an important role in the aetiology of eclampsia.

\section{KEYWORDS}

Eclampsia, Placenta, Foetus, IUGR, APGAR, Microscopic Changes.

HOW TO CITE THIS ARTICLE: Kodiplackal MS, Chettoor P. Foetomaternal outcome and placental changes in eclamptic patients. J. Evolution Med. Dent. Sci. 2017;6(17):1348-1351, DOI: 10.14260/Jemds/2017/293

\section{BACKGROUND}

Hypertensive disorders such as preeclampsia are one of the commonest complications encountered during pregnancy. They occur in 5-10\% of all pregnancies. Onset of convulsions in a woman with preeclampsia that cannot be attributed to any other cause is termed eclampsia. In addition to the maternal morbidity and mortality, hypertensive disorders of pregnancy are strongly associated with foetal growth restrictions and prematurity, thereby contributing to perinatal morbidity and mortality. In recent years, placenta has drawn attention as a valuable indicator of neonatal and maternal well-being and disease. Placental weight, diameter and lesions tend to correlate well with severity of maternal and foetal morbidity and mortality. Placentae of eclamptic women are smaller, lighter and changes like infarction and calcification are also seen more frequently. Severity of changes is proportionate to the severity of disease.

In view of increasingly significant recognition of the role of placenta as a gauge of neonatal and maternal health, this study was performed to assess the microscopic and

Financial or Other, Competing Interest: None.

Submission 06-02-2017, Peer Review 18-02-2017,

Acceptance 20-02-2017, Published 27-02-2017.

Corresponding Author:

Dr. Moly Sam Kodiplackal,

Assistant Professor,

Department of Obstetrics and Gynaecology,

IMCH, Government Medical College,

Kozhikode-673008, Kerala.

E-mail: drmolysamk@gmail.com

DOI: $10.14260 /$ jemds $/ 2017 / 293$ macroscopic changes seen in placenta of eclamptic women and also to study the association between placental changes and maternal and foetal morbidity and mortality.

\section{MATERIALS AND METHODS}

This case control study was conducted in the Institute of Maternal and Child Health in Government Medical College, Calicut, Kerala, from $1 / 1 / 2011$ to $31 / 12 / 2011$, and there were 48 cases of Eclampsia. Of the 48 cases of eclampsia, 43 were antepartum, two intrapartum and three were postpartum eclampsia.

90 subjects were selected for the study. Of the 90,45 were cases and 45 were controls. Subjects chosen as cases had antepartum and intrapartum eclampsia whereas subjects in the control group were normal cases without any medical or obstetric complications.

After obtaining a written informed consent from the subject, relevant clinical history was obtained and a detailed clinical examination was carried out according to proforma and data was recorded. The subjects were followed through their labour and delivery and the progress of the babies during labour, delivery and post-delivery was also recorded.

After delivery, placenta was collected from each case and control. Placenta was washed in tap water to remove excess blood and dried using blotting paper. Any abnormality of cord, membranes or placenta was noted. Umbilical cord was cut close to its insertion to placenta. Excess membranes were trimmed off. Placental weight was measured. Mean placental diameter was also measured and surface area was calculated. After measurements were taken, placenta was fixed in $10 \%$ 
formalin solution. 1 to 3 days were required for fixation. Then, multiple biopsies were taken from abnormal areas, close to cord insertion and from periphery.

Histological examination was performed at the Department of Pathology, Government Medical College, Calicut. Paraffin blocks were prepared, sections were cut and stained with haematoxylin and eosin. Changes like calcification, retroplacental clot formation and intervillous fibrin deposition were noted. After delivery, the baby was also examined and APGAR score and birth weight were noted and those who needed critical care were admitted in the NICU.

All the data recorded were entered into an excel sheet. The data was compiled and subjected to statistical analysis using SPSS 16.0 software. Unpaired ' $t$ ' test was used for comparison of data between cases and controls. Correlation between the placental macroscopic parameters and foetal and maternal outcome was done using Pearson's correlation coefficient.

\section{RESULTS}

During the study period of one year, the incidence of eclampsia was $0.32 \%$ in IMCH, Calicut, which is lower than the national average of $1.5 \%$. Majority of the cases of eclampsia occurred in the age group of $18-24$ years $(51.1 \%)$, the same age group also formed $48.89 \%$ of controls which supports the trend in Kerala towards late child bearing. The average age of cases was 25.04 years and 24.68 years for controls while the average age of child bearing in India is 21 years. 11 cases and 3 controls had $\mathrm{Hb}$ less than 10.18 cases had $\mathrm{Hb}$ more than 12 and none of the controls had reduced Hb. Haemoconcentration (Hct>42) was seen in 19 cases. Haemoconcentration is considered a hallmark of eclampsia.

Eclampsia is considered a disease of primigravida, but in this study almost similar numbers occurred in primigravida and multigravida (Table 1). Only $15.5 \%$ of eclampsia occurred in booked patients who had antenatal care at IMCH, the rest were referred from other hospitals. Only one case $(2.2 \%)$ had no antenatal check-up. Seven cases were booked and 38 cases were referred. Only 10 controls were referred and 35 controls were booked (Table 2).

The mean birth weight of babies born to cases was $1.5 \mathrm{Kg}$, with standard deviation (S.D.) of 0.57 and that of babies of controls was $2.84 \mathrm{Kg}$ with standard deviation (S.D.) of 0.49 . When unpaired t-test was done, this difference was found to be statistically significant $(\mathrm{p}<0.05) .4 .4 \%$ babies in case group weighed $<1 \mathrm{Kg}$. $33.33 \%$ of cases delivered babies weighing between $1.5-2.5 \mathrm{Kg}$ and $37.78 \%$ of babies were between $1-1.5 \mathrm{Kg}$. There were 10 cases of intrauterine foetal demises $(22.22 \%)$. In controls, only 13 babies were less than $2.5 \mathrm{Kg}$. This study found that babies with reduced birth weight were significantly more in eclampsia group when compared to controls (Table 3).

Eighteen babies with APGAR less than 5 in 1 minute belonged to eclamptic women which included 10 cases of intrauterine demise of foetuses. Two cases had APGAR 5-7 in 1 minute. Only three babies in control group had APGAR less than 7 in 1 minute (Table 4). When unpaired t-test was done, there was a statistically significant decrease in placental weight of babies with APGAR less than 7 and those with APGAR more than 7. Of the babies born in eclampsia group, $15.56 \%$ had APGAR < 5 in 1 minute, whereas only 3 babies in control group had APGAR < 5 in 1 minute. Majority (62.2\%) of the eclampsia babies required neonatal ICU admission when only $13.33 \%$ of controls needed it. Also, there were 10 (22.22\%) intrauterine demises, 15 (33.33\%) neonatal demises in the case group.

28 babies of cases had NICU admission. Of the 17 who were not admitted, 10 were cases of intrauterine foetal demise. Only 6 control babies were admitted in NICU (Table 5). Maternal complications developed included: PRES (6.67\%), abruption placentae (4.44\%), HELLP syndrome (15.56\%). 11.11\% developed multiple complications. Maternal complications were seen in 21 of the 45 cases. Four of the cases had multiple complications. But on discharge from hospital only 3 cases had hypertension (Table 6).

A significant reduction was found in the placental diameter and percentage surface area in eclamptic cases compared to controls. An association was found between reduction in placental weight and increased NICU admission which was not significant. The area involved in infarction was also increased in cases compared to controls.

On statistical analysis, the mean placental weight in patients with eclampsia was $281.96 \mathrm{~g}$ and in controls was $450.53 \mathrm{~g}$ with S.D. of 99.59 \& 63.09 respectively. The difference in placental weight was found to be statistically significant ( $p<0.05$ ) (table 7). The average placental weight in intrauterine foetal demise cases was $228.5 \mathrm{~g}$, in neonatal death cases was $250.9 \mathrm{~g}$ and the average placental weight in cases with babies healthy on discharge was $332 \mathrm{~g}$. (Graph 1).

No correlation was found between placental weight and NICU admissions (Table 8). But significant correlation was found between placental weight and birth weight (Table 8). A linear correlation was observed between placental weight and birth weight of babies. The mean placental diameter in cases was $8.75 \mathrm{~cm}$ and in controls was $16.2 \mathrm{~cm}$ with S.D. of 2.33 and 2.11 respectively. The difference in placental diameter was statistically significant with $p$ value $<0.05$ (Table 7) (Graph 2).

The mean surface area for cases was 64.29 square $\mathrm{cm}$ and for controls, it was 209.4 square $\mathrm{cm}$ with standard deviations of 32.1 and 54.7 respectively, this difference was statistically significant with $p$ value $<0.05$. It was seen that 10 of the cases had Grade 3 infarction while only 1 control had the same. 23 cases had Grade 2 infarction and 13 controls had Grade 2 infarction. Grade 1 infarction was seen in 12 of the cases and 31 of the controls. On histopathological examination, there was higher incidence of changes like calcification, retroplacental clot formation and intervillous fibrin deposition in cases than in controls.

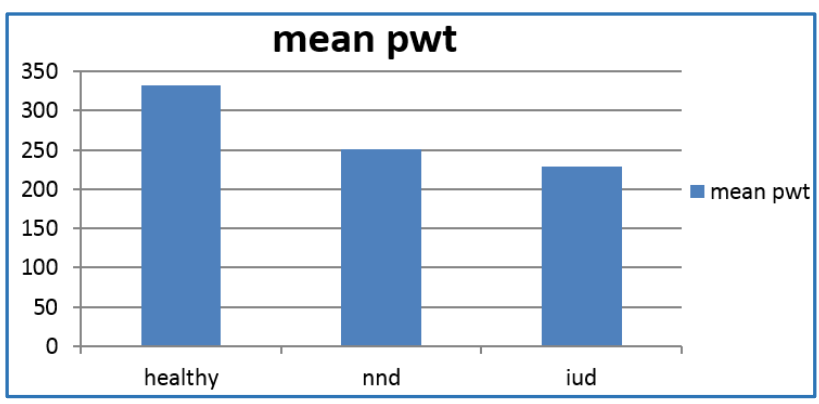

Graph 1. Distribution based on Average Placental Weight in Healthy, NMD and IUD Foetus 


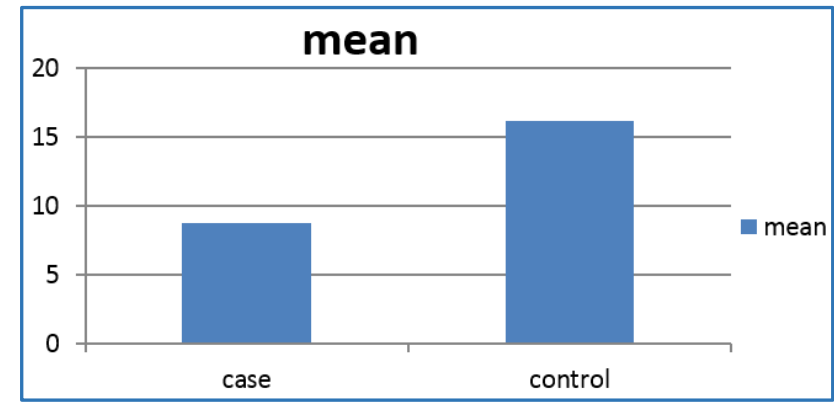

Graph 2. Distribution based on Mean Placental Diameter

\begin{tabular}{|c|c|c|}
\hline Parity & Case & Control \\
\hline Primi & 23 & 22 \\
\hline Multi gravida & 22 & 23 \\
\hline $\begin{array}{c}\text { Table 1. Distribution based on Parity shows Eclampsia is } \\
\text { almost equal in Primi and Multigravida }\end{array}$ \\
\hline
\end{tabular}

\begin{tabular}{|c|c|c|}
\hline Booked/Referred & Case & Control \\
\hline Booked & 7 & 35 \\
\hline Referred & 38 & 10 \\
\hline Table 2. Distribution based on Booked/Referred cases \\
shows increased Incidence in Referred Cases \\
\hline
\end{tabular}

\begin{tabular}{|c|c|c|}
\hline Birth Weight & Case & Control \\
\hline$<1 \mathrm{Kg}$ & 2 & 0 \\
\hline $1-1.5 \mathrm{Kg}$ & 17 & 0 \\
\hline $1.5-2.5 \mathrm{Kg}$ & 15 & 13 \\
\hline$>2.5 \mathrm{Kg}$ & 11 & 32 \\
\hline
\end{tabular}

Table 3. Distribution of cases based on Birth Weight of Babies shows that LBW babies were more in Eclampsia

\begin{tabular}{|c|c|c|}
\hline APGAR & Case & Control \\
\hline 0 & 10 & 0 \\
\hline$<5$ & 8 & 0 \\
\hline 5 to 7 & 2 & 3 \\
\hline$>7$ & 25 & 42 \\
\hline \multicolumn{2}{|c|}{ Table 4. Distribution based on APGAR Score } \\
\hline
\end{tabular}

\begin{tabular}{|c|c|c|}
\hline & Case & Control \\
\hline NICU Admission & 28 & 6 \\
\hline No NICU Admission & 17 & 39 \\
\hline \multicolumn{2}{|r|}{ Table 5. Distribution based on NICU Admission } \\
\hline
\end{tabular}

\begin{tabular}{|c|c|}
\hline Maternal Complications & No. of Cases \\
\hline PRES & 3 \\
\hline HELLP & 10 \\
\hline ABRP & 5 \\
\hline ATN & 2 \\
\hline DIC & 1 \\
\hline \multicolumn{2}{|c|}{ Table 6. Distribution based on Maternal Complications } \\
\hline
\end{tabular}

\begin{tabular}{|c|c|c|c|}
\hline Parameter & Cases & Controls & P Value \\
\hline Birth Weight & $1.5 \pm 0.57$ & $2.84 \pm 0.49$ & $<0.05^{*}$ \\
\hline $\begin{array}{c}\text { Placental } \\
\text { Diameter }\end{array}$ & $8.75 \pm 2.33$ & $16.2 \pm 2.11$ & $<0.05^{*}$ \\
\hline $\begin{array}{c}\text { Placental } \\
\text { Weight }\end{array}$ & $281.96 \pm 99.59$ & $450.53 \pm 63.09$ & $<0.05^{*}$ \\
\hline $\begin{array}{c}\text { Mean Surface } \\
\text { Area }\end{array}$ & $64.29 \pm 32.1$ & $209.4 \pm 54.7$ & $<0.05^{*}$ \\
\hline \multicolumn{4}{|c|}{$\begin{array}{c}\text { Table 7. Unpaired 't' test for Comparison } \\
\text { of data between Cases and Controls }\end{array}$} \\
\hline
\end{tabular}

*Denotes Significant Difference.

\begin{tabular}{|c|c|c|}
\hline Parameter & NICU Admissions & Birth Weight \\
\hline Placental Weight & 0.106 & $0.98^{*}$ \\
\hline \multicolumn{2}{|c|}{ Table 8. Correlation between the Placental Macroscopic } \\
Parameters and Foetal and Maternal Outcome \\
\hline
\end{tabular}

*Denotes Significant Correlation

\section{DISCUSSION}

This case control study spanned over a period of 12 months from $1 / 1 / 2011$ to $31 / 12 / 2011$, there were 14,888 deliveries of which there were 48 cases of eclampsia. During this period, the incidence of eclampsia was $0.32 \%$ in IMCH, Calicut. 90 subjects were selected for the study. The sample size was calculated so as to achieve power of the study as $80 \%$ with an alpha error of $5 \%$. Of the 90,45 were cases and 45 were controls. The average age of cases was 25.04 years and 24.68 years for controls while the average age of child bearing in India is 21 years.

Of the 45 cases, 33 had history of hypertension or history of hypertension in previous pregnancy. 32 cases had impending symptoms before they developed convulsions (71\% experienced different types of impending symptoms before the onset of seizures). In 31 of the cases, hypertension was detected prior to admission and were placed on treatment. 43 cases developed convulsions prior to admission i.e. $73 \%$ of cases were already diagnosed to have increased blood pressure and $93 \%$ were on medication by the time they developed seizures. Only 2 (4.44\%) cases developed intrapartum eclampsia after admission. Maximum number of seizures suffered was three in a single patient, of which two occurred after admission.

It was seen from the study that 11 cases were anaemic and 19 cases had haemoconcentration. Urine albumin level was high in 41 of 45 cases. Majority of the cases occurred in the 18-24 age groups. Although eclampsia is considered a disease of primigravida, in this study almost similar numbers occurred in primigravida and multigravida. Eclampsia was more common in the low socioeconomic group, $62.22 \%$ of cases occurred in the low socioeconomic group, a finding also observed by others like Akhtar, who found $72 \%$ of the cases in the low socioeconomic group.(1)

Only $15.5 \%$ of eclampsia occurred in booked patients at $\mathrm{IMCH}$, the rest were referred from other hospitals i.e., 38 of the cases were referred. Only one case $(2.2 \%)$ had no antenatal check-up. Akhtar,(1) in his study, found that $60 \%$ of eclampsia cases occurred in patients with no antenatal care. Rajasri(2) also found similar findings in her study.

Of the 45 cases, 41 were preterm i.e. $91.1 \%$ of babies of cases were premature, of which 15 were at less than 32 weeks ( $33.3 \%$ cases in < 32 weeks) and three at less than 28 weeks. Only seven controls were preterm. On admission, $66.6 \%$ had clinical evidence of IUGR, which increased to $75.55 \%$ after delivery (birth weight $<2.5 \mathrm{Kg}$ ). Only $24.44 \%$ of cases delivered babies weighing $>2.5 \mathrm{Kg}$ whereas $28.89 \%$ of controls delivered babies weighing < $2.5 \mathrm{Kg} .4 .4 \%$ babies in case group weighed $<1 \mathrm{Kg}$. $33.33 \%$ of cases delivered babies weighing between $1.5-2.5 \mathrm{Kg}$ and $37.78 \%$ of babies were between $1-1.5 \mathrm{Kg}$. There were 10 cases of intrauterine foetal demise (22.22\%).

This study found statistically significant reduction in birth weight of babies born in eclampsia group when compared to controls. Similar results were observed by S. Gupta(3), 
P.Navbir,(4) Kishwara(5) and S. Majumdar.(6) Rajasri(2) observed that perinatal mortality is higher in babies weighing $<2 \mathrm{Kg}$. Of the babies born in eclampsia group, $15.56 \%$ had APGAR $<5$ in 1 minute, and only 3 babies in control group had APGAR < 5 in 1 minute. Majority (62.2\%) of the eclampsia babies required NICU admission when only $13.33 \%$ of controls needed it. There were 10 (22.22\%) IUD, $15(33.33 \%)$ NND cases in the case group. Templeton,(7) Udainia and Jain ${ }^{(8)}$ observed that $1 / 6$ of eclampsia resulted in still births. They also observed a reduction in mean birth weight. Rajasri(2) observed an increase in perinatal mortality in eclampsia. Maternal complications were seen in 21 of the 45 cases and 3 cases had hypertension at the time of discharge

A linear correlation was observed between placental weight and birth weight of babies. Udainia and Jain observed similar relation in pre-eclampsia and eclampsia.(8) Significant reduction was found in the placental diameter and percentage surface area in eclamptic cases compared to controls. Studies by Barua,(9), Sengupta,(3) Udainia(10) and Majumdar(6) observed similar reductions in placental weight, diameter and percentage surface area in preeclampsia and eclampsia. Significant correlation was found between reduction in placental weight and increased NICU admission. The area involved in infarction was also increased in cases compared to controls which was also seen by Salgado,(11) Udainia,(10) Majumdar(6).

On histopathological examination, there was higher incidence of changes like calcification, retroplacental clot formation and intervillous fibrin deposition. Udainia and Jain(4) found that at least some degree of calcification was present in almost $100 \%$ of severe preeclampsia cases including eclampsia. Studies by Salgado,(11) Majumdar,(6) Navbir(4) also support this.

\section{CONCLUSION}

It was seen in this study that eclampsia is common in lower socioeconomic group. Eclampsia resulted in more preterm, low birth weight infants. The decrease in placental weight, diameter and surface area is significantly associated with eclampsia and adverse foetal outcome. Microscopic changes such as infarction, RP clot, intervillous fibrin and calcification is significantly associated with eclampsia. Considering the microscopic and macroscopic changes in the placenta in eclamptic women, it may be hypothesised that the placenta may have an important role in aetiological process of eclampsia. Placenta may give significant information on the foetal outcome also. However, further studies on larger groups are necessary to arrive at a definitive conclusion.

\section{REFERENCES}

[1] Akhtar R, Ferdous A, Bhuiyan SN. Maternal and fetal outcome of eclamptic patients in a tertiary hospital. BJOG 2011;26(2):77-80.

[2] Yaliwal RG, Jaju PB, Vanishree M. Eclampsia and perinatal outcome: a retrospective study in a teaching hospital. JCDR 2011;5(5):1056-9.

[3] Gupta S, Gupta P. Correlation of placental weight and fetal outcome in pregnancy induced hypertension. IJABMS 2012;14B(19):76-82.

[4] Navbir P. Placental morphology and its correlation with fetal out come in pregnancy induced hypertension. IJBAMS 2012;2(3):120-5.

[5] Kishwara S, Nurunnabi ASM, Begum M, et al. Effect of Maternal Pre-eclampsia on the Weight of the Placenta. BJA 2010;8(2):69-71.

[6] Majumdar S, Dasgupta H, Bhattacharya K. A study of placenta in normal and hypertensive pregnancies. JASI 2005;54(2):1-9.

[7] Templeton A, Campbell D. A retrospective study of eclampsia in the Grampian region, 1965-1977. Health Bullletin 1979;37(2):55-9.

[8] Udainia A, Jain ML. Morphological study of placenta in pregnancy induced hypertension with its clinical relevance. JASI 2001;50(1):24-7.

[9] RB. Macroscopic and microscopic changes in human placenta in gestational diabetes and eclampsia. Bangabandu Sheik Mujib Medical University, Dhaka, 2002.

[10] Udainia A, Bhagwat SS, Mehta CD. Relation between placental surface area, infarction and foetal distress in pregnancy induced hypertension with its clinical relevance. JASI 2004;53(1):27-30.

[11] Salgado SS, Salgado MKR. Structural changes in preeclamptic and eclamptic placentas--ultrastructural study. JCPSP 2011;21(8):482-6. 